\title{
Introductory Chapter: Recycling and Reuse of End-of- Life Carbon Fibre Reinforced Polymers
}

\author{
Rita Khanna \\ Additional information is available at the end of the chapter \\ http://dx.doi.org/10.5772/intechopen.76709
}

\section{Introduction}

Industrial carbon-bearing waste from airliners, trains, cars, boats, turbine blades, sporting, industrial and commercial goods is very hard to recycle or reshape into original components $[1,2]$. Carbon fibre-reinforced polymers (CFRPs) ( $>90 \%$ carbon) contain significant fraction of carbon fibres within a polymer matrix, along with varying levels of additives such as silica, alumina and other minerals. Carbon fibres contribute towards high tensile strength, whereas the matrix provides the impact strength [3]. Their key characteristics such as long-term thermal stability, rigidity, dimensional stability, resistance to creep and deformation under load, high electrical and thermal insulating properties and other advantages play an important role in their various applications; however, these create major bottlenecks for their end-of-use disposal $[4,5]$. These fire-resistant materials that are designed to resist combustion contain large amounts of pure, disordered carbon with a complex bond network and are difficult to recycle by conventional means.

Aeronautics is one of the biggest consumers of CFRPs due to the recent developments in planes, for example, Boeing 787, Airbus A380 and A350, whereas the growth in the automotive sector is somewhat slow. According to the International Civil Aviation Organisation, the global air transport network has been observed to double in size every 15 years. It is estimated that $44 \%$ of the global fleet of commercial, military and private aircrafts is likely to reach end of life in 20 years or so; between 400 and 600 commercial aircraft are disassembled around the world each year [6]. A cost-effective environmentally sustainable management of large volumes of CFRPs' waste from end-of-life products therefore assumes great significance and urgency.

Protecting the environment for future generations is a fundamental issue and a great challenge; manufacturers are seeking alternatives approaches of waste management. 
Key challenge is to find environmentally friendly, alternative recycling approaches and to transform carbon-bearing composite waste into valuable resources. Recycling rates for CFRPs are currently very low, with most of the waste ending up in landfills. While landfilling is a relatively cheap and convenient disposal route, environmental legislation on waste management is also becoming increasingly restrictive.

According to the European Union's Waste Framework Directive [7], landfilling is the least preferred waste management option. Landfilling carbon-bearing waste can be a serious environmental hazard as well. It can lead to the release of greenhouse gases, including huge amounts $\mathrm{CO}_{2}$ and methane; up to $50 \%$ of these emissions are of methane, which is 21 times more potent a greenhouse gas than $\mathrm{CO}_{2}$. Manufacturers across Europe are required to pay to dispose their production waste if it goes to landfill as well as a climate change levy.

Current approaches for recycling composite materials, reuse and material recovery from waste CFRPs are briefly reviewed in the following section. While several techniques such as pyrolysis, solvolysis, mechanical grinding, chemical, high voltage fragmentation and so on using different approaches have shown feasibility of recycling, commercial/industrial applications of recycled carbon fibres are still very limited. Recycled fibres are generally of lower quality as compared to virgin fibres due to lack of control in fibre length and length distribution, diminished surface quality and multiple sources [8].

Recycling is profitable and sustainable only if the value of the reclaimed materials exceeds the cost of the recycling process. Recycled carbon fibres can be $30-40 \%$ cheaper than virgin carbon fibres; however, the degradation of fibre characteristics can be a serious issue during reuse. Process conditions are known to vary significantly depending on the waste CFRP products being recycled. Composite waste, generally sourced across different industries, is also likely to be heterogeneous in nature. A new approach based on using waste CFRPs as a carbon resource in steelmaking will be presented, especially for those CFRPs that cannot be transformed back in to carbon fibres.

\section{Recycling approaches for waste CFRPs}

Various approaches for recycling and reusing waste CFRPs as carbon fibres as well as a carbon resource are briefly reviewed in this section.

\subsection{Mechanical recycling}

The key principle of recycling CFRPs involves the separation of carbon fibres from the resin matrix.

Mechanical processing involves crushing and shredding followed by further grinding and milling down to 10-50 mm of fine particles [9]. Recovered materials/flakes are separated into resin-rich powders and carbon fibres of different lengths still embedded in the resin matrix. Resin-rich powders find applications as fillers in bulk as well as sheet-melding composites [10]. While recovered fibre-rich fractions find reuse in composites [11], their cost and quality are key factors affecting efficient reuse. 
Cutting mills were found to produce longer as well as more homogeneous fibre lengths as compared to hammer mills [12]. Direct reforming without grinding has also been used in some cases. Due to significant impairment in mechanical properties and poor bonding between the fibrous fraction and resin, recycled materials are still being used in small concentrations only [13]. Electrodynamic fragmentation has been used to shred carbon fibre-reinforced thermoplastics. Milling dust and chips produced during milling operations have found applications as fillers in the production of thermoplastic granulates with increase in tensile strength and overall rigidity [14]. Degradation in carbon fibre quality is a key issue affecting mechanical processing.

\subsection{Thermal processing}

A variety of thermal processes including pyrolysis (heating in the absence of air), fluidised bed and microwave-assisted pyrolysis as well as combustion (heating in the presence of oxygen) have been used for recycling CFRPs [15-17]. Key purpose of these processes is to devolatilize resin to recover carbon fibres; typical temperatures used range between 450 and $700^{\circ} \mathrm{C}$ depending on the resin used. As high temperatures $\left(>2200^{\circ} \mathrm{C}\right)$ are used in the preparation of carbon fibres, relative lower pyrolysis temperatures do not have much effect on basic characteristics of carbon fibres.

Temperatures up to $1550^{\circ} \mathrm{C}$ are used for recycling of CFRPs for steelmaking applications [18]. Devolatilised resin produces $\mathrm{CO}_{2}, \mathrm{H}_{2}, \mathrm{CH}_{4}$ gases, an oily fraction as well as char that may deposit on fibre surfaces. Key advantages of pyrolysis (temperature range: $400-1550^{\circ} \mathrm{C}$ ) include retention of mechanical properties, recovery of carbon fibres and the absence of chemicals. Some of the detrimental factors include the deposition of chars on fibre surfaces and hazardous emissions due to thermal degradation of resin [18].

While higher amounts of energy may be consumed during pyrolysis depending on operating temperatures, this process does not cause local area contamination, typically associated with mechanical and physical processing of waste. Deposition of char from degraded resin can be seen clearly in SEM images of CFRPs treated at a range of temperatures (Figure 1). The fibres contaminated by resin char require additional heating in air at $450^{\circ} \mathrm{C}$ to burn this residual char. However, oxidation can cause strength degradation (up to $50 \%$ ), shorter fibres and unstructured fibre architecture [20].

In microwave-assisted pyrolysis, direct heating of the material core in inert atmosphere results in fast thermal transfer and energy savings. Lester et al. [17] suspended specimens of carbon fibres and resin in a microwave cavity using quartz sand to suspend the samples and glass wool to limit material loss. Using a bed of silica sand, fluidised bed reactor used hot air for rapid heating and dissociation of resin from the CFRPs matrix [12]. A strength degradation of $~ 25 \%$ was recorded for carbon fibres after heat treatment at $550^{\circ} \mathrm{C}$. While this technique can process contaminated as well as end-of-life waste, it is not particularly suitable for recovering carbon fibres.

\subsection{Solvolysis}

Solvolysis involves chemical degradation of the resin present in CFRPs with the help of chemical solvents. Water is the most commonly used solvent; organic co-solvents, alkaline as well as 

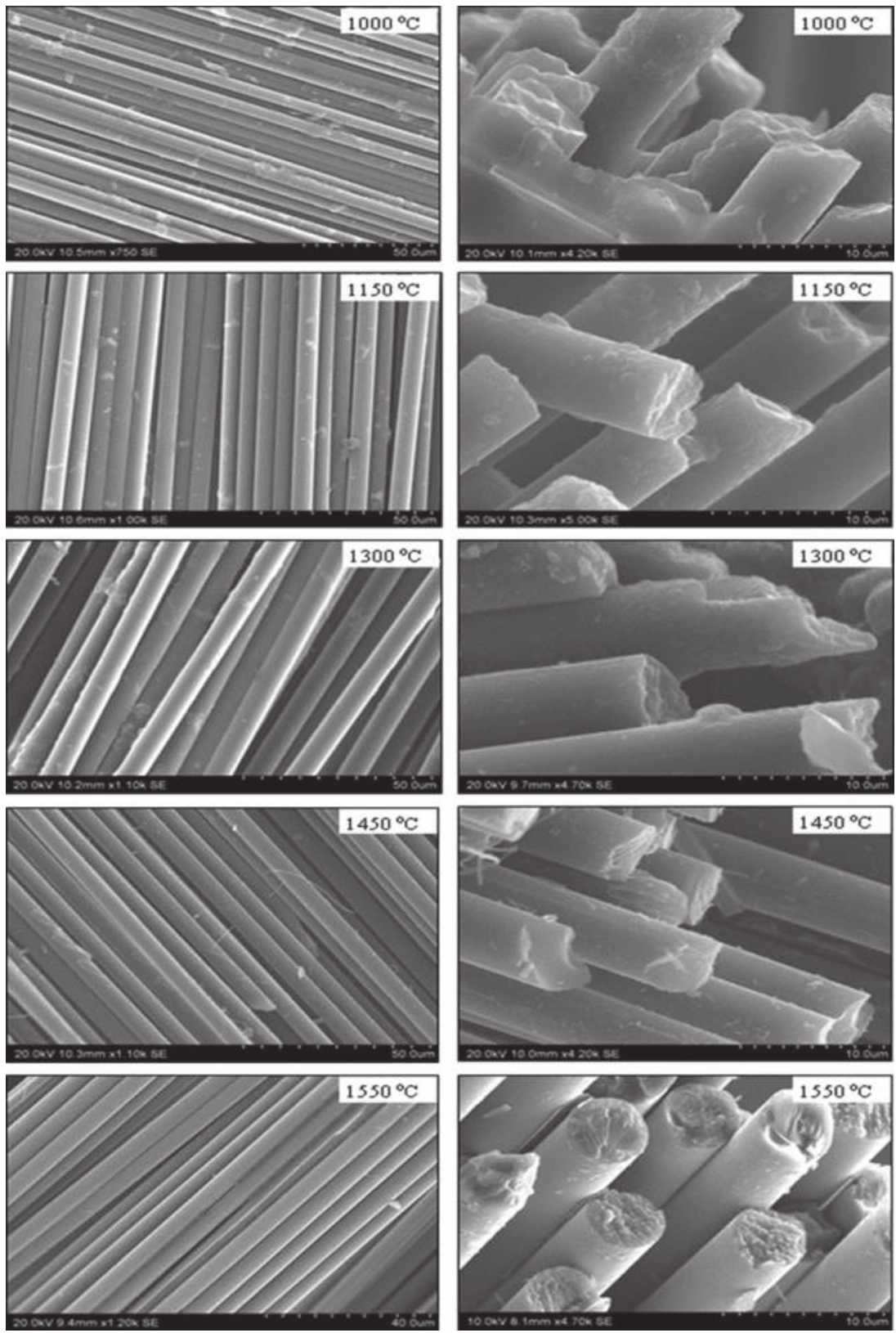

Figure 1. Scanning electron microscopy (SEM) images on pyrolysis residues from CFRPs heat treated at a range of temperatures [19]. Low (left) as well as high (right) resolution images have been presented.

acidic catalysts, are also used along with water depending on the nature of the resin involved [21-23]. Low temperatures as well as pressures are used sometimes in conjunction with various solvents; polyester resins require lower temperatures than epoxy resins for degradation 
and solvolysis. The overall process can therefore be a combination of solvolysis and thermal processes, for example, hydrothermal processes for use of water at higher temperatures.

It is also possible to modify the solvent power and basic characteristics, reactivities and so on by operating under subcritical or supercritical conditions as a function of temperature and pressure [24]. These techniques can recover carbon fibres without much detriment of fibre lengths, distributions and mechanical properties. However, these may not be suitable for contaminated waste or could cause environmental damage when hazardous chemicals are either used or produced as spent byproducts.

\subsection{Waste CFRPs as a carbon resource}

Significant research has been carried out on recycling waste CFRPs in attempts to extract carbon fibres, albeit with reduced mechanical and other capabilities, for further reutilization in a variety of lower-grade applications. As recycling rates continue to be very low and landfilling not a viable option due to high costs and/or legislation, the utilisation of waste CFRPs as a carbon resource in steelmaking is being explored [25]. This technique can process waste CFRPs irrespective of the nature and characteristics of fibres, resin and impurities present due to high temperatures $\left(1550^{\circ} \mathrm{C}\right)$.

CFRPs typically contain up to $92 \mathrm{wt}$.\% carbon in form of fibre; fibres containing up to $99 \mathrm{wt} . \%$ carbon is generally known as graphite fibres. The atomic structure of carbon fibres is similar to graphite and consists of sheets of carbon atoms (graphene sheets) arranged in a regular hexagonal pattern, the key difference being the manner of interlocking between sheets. Precursors used to prepare carbon fibres have a strong influence on atomic-level fibre structure [26].

Carbon fibres derived from polyacrylonitrile (PAN) have a turbostratic structure (random orientation of graphene sheets), whereas carbon fibres derived from the mesophase pitch have a highly ordered graphitic structure. As a potential carbon resource for steelmaking, waste CFRPs have better characteristics as compared to typical carbons, for example, coals, cokes, chars and so on [27].

Carbon dissolution from CFRP powders into molten iron was investigated at $1550^{\circ} \mathrm{C}$ using sessile drop arrangement [28]. Carbon dissolution investigations showed a rapid carbon pickup reaching $\sim 5.20 \mathrm{wt}$ \% carbon for CFRPs char $\left(\mathrm{K}: 22.2 \times 10^{-3} \mathrm{~s}^{-1}\right)$ within $2 \mathrm{~min}$. This level of carbon pickup was similar to that from synthetic graphite and was much higher than typical results from coke, coal chars and natural graphite.

End-of-life waste CFRPs can be used as an alternative source of carbon for carburising purposes in steelmaking. Such sustainable recycling of CFRP materials for the steelmaking industry will be an important pathway towards solving CFRPs' disposal problems such as waste management and landfilling. This research is presently in initial stages. Significant testing and development will be required for commercial-scale applications.

\section{Concluding remarks}

A brief review has been presented on recycling CFRPs, recovering carbon fibres as reusable products, degradation of fibre characteristics after mechanical, thermal and chemical 
processing of waste. Significant success has been achieved using a wide variety of techniques depending on the nature/type of resin used, fibre precursors, manufacturing source and waste CFRP products being recycled. Commercial industrial scale recycling is not yet economically feasible in most cases. Utilisation of waste CFRPs as an alternate carbon resource in steelmaking is an emerging technology that could reduce the carbon footprint of the steel sector and help redirect this carbonaceous waste from landfills and associated economic and environmental impact.

\section{Author details}

\section{Rita Khanna}

Address all correspondence to: rita.khanna66@gmail.com

Centre for Sustainable Materials Research and Technology, School of Materials Science and Engineering, UNSW Australia, Sydney, NSW, Australia

\section{References}

[1] Goodship V, editor. Management, Recycling and Reuse of Waste Composites. Cambridge, England: Woodhead Publishing Co.; 2008

[2] Marsh G. Reclaiming value from post-use carbon composite. Reinforced Plastics. 2008; 52:36-39

[3] Chawla KK. Composite Materials: Science and Engineering. New York: Springer-Verlag; 1998

[4] Kubota Y, Furuta T, Aoki T, Ishida Y, Ogasawara T, Yokota R. Long-term thermal stability of carbon fibre-reinforced addition-type polyimide composite in terms of compressive strength. Advanced Composite Materials. 2018. DOI: 10.1080/09243046.2018.1446124

[5] Recycling Carbon Fibres from the Composite Industry. 2005. Available from: http:// www.jeccomposites.com/composites-news/1741/carbon-fibres.html

[6] Ribeiro JS, Oliveira Gomes J. Proposed framework for end-of-life aircraft recycling. Procedia CIRP. 2015;26:311-316

[7] Jacob A. Composites can be recycled. Reinforced Plastics. 2011;55:45-46

[8] McConnell VP. Launching the carbon fibre recycling industry. Reinforced Plastics. 2010; 54:33-37

[9] Molnar A. Recycling advanced composites. Final Report for the Clean Washington Center (CWC). December 1995 
[10] Oliveux G, Dandy LO, Leeke GA. Current status of recycling of fibre rein1forced polymers: Review of technologies, reuse and resulting properties. Progress in Materials Science. 2015;2072:61-99

[11] Palmer J, Savage L, Ghita OR, Evans KE. Sheet moulding compound (SMC) from carbon fibre recyclate. Composites Part A Applied Science Manufacturing. 2010;41:1232-1237

[12] Pickering SJ. Recycling technologies for thermoset composite materials - Current status. Composites Part A Applied Science and Manufacturing. 2006;37:1206-1215

[13] Schinner G, Brandt J, Richter H. Recycling carbon-fiber-reinforced thermoplastic composites. Journal of Thermoplastic Composite Materials. 1996;9:239-245

[14] Uhlmann E, Meier P. Carbon fibre recycling from milling dust for the application in short fibre reinforced thermoplastics. Procedia CIRP. 2017;66:277-282

[15] Meyer LO, Schulte K. CFRP-recycling following a pyrolysis route: Process optimization and potentials. Journal of Composite Materials. 2009;43:1121-1132

[16] López FA, Rodríguez O, Alguacil FJ, García-Díaz I, Centeno TA, García-Fierro J. Recovery of carbon fibres by the thermolysis and gasification of waste prepeg. Journal of Analytical Applied Pyrolysis. 2013;104:675-683

[17] Lester E, Kingman S, Wong KH, Chris R, Pickering S, Hilal N. Microwave heating as a means for carbon fibre recovery from polymer composites: A technical feasibility study. Material Research Bulletin. 2004;39:1549-1556

[18] Pimenta S, Pinho ST. Recycling carbon fibre reinforced polymers for structural applications: Technology review and market outlook. Waste Management. 2011;31:378-392

[19] Mansuri I, Khanna R, Sahajwalla V. Recycling carbonaceous industrial/commercial waste as a carbon resource in steelmaking. Steel Research International. 2017;88:1600333

[20] Markovic V, Marinkovic S. A study of pyrolysis of phenolic resin reinforced with carbon fibres and oxidized PAN fibres. Carbon. 1980;18:329-335

[21] Fromonteil C, Bardelle P, Cansell F. Hydrolysis and oxidation of an epoxy resin in suband supercritical water. Industrial Engineering Chemistry Research. 2000;39:922-925

[22] Iwaya T, Tokuno S, Sasaki M, Goto M, Shibata K. Recycling of fibre reinforced plastics using depolymerization by solvothermal reaction with catalyst. Journal of Materials Science. 2008;43:2452-2456

[23] Yang P, Zhou Q, Yuan XX, van Kasteren JMN, Wang YZ. Highly efficient solvolysis of epoxy resin using poly(ethylene glycol)/NaOH systems. Polymer Degradation Stability. 2012;97:1101-1106

[24] Wu BC, Klein MT, Sandler SI. Solvent effects on reactions in supercritical fluids. Industrial Engineering Chemistry Research. 1991;30:822-828 
[25] Mansuri I. Recycling waste polymers as a source of carbon in steelmaking: Fundamental high temperature investigations on structure evolution and carbon dissolution into molten iron. [PhD thesis]. Sydney, Australia: University of New South Wales; 2015

[26] Huang X. Fabrication and properties of carbon fibers. Materials. 2009;2:2369-2403

[27] Sahajwalla V, Dubikova M, Khanna R. Reductant characterisation and selection: Implications for ferroalloys processing. Proceedings of 10th International Ferroalloys Congress. Capetown, South Africa: South African Institute of Mining and Metallurgy; 2004. p. 2

[28] Rahman M, Khanna R, Sahajwalla V, O'Kane P. The influence of ash impurities on interfacial reactions between carbonaceous materials and EAF slag at $1550^{\circ} \mathrm{C}$. ISIJ International. 2009;49:329-336 